\title{
Níveis de treonina digestível em dietas para fêmeas suínas lactantes de médio potencial genético
}

\author{
Charles Kiefer ${ }^{1}$, Aloizio Soares Ferreira ${ }^{2}$, Juarez Lopes Donzele ${ }^{2}$, Rita Flávia Miranda de \\ Oliveira $^{2}$, Francisco Carlos de Oliveira Silva ${ }^{3}$, Alfredo Sampaio Carrijo ${ }^{1}$ \\ 1 DZO/FAMEZ/Universidade Federal de Mato Grosso do Sul - Campo Grande/MS \\ 2 DZO/CCA/Universidade Federal de Viçosa - Viçosa/MG. \\ ${ }^{3}$ EPAMIG - Viçosa/MG
}

RESUMO - Foram utilizadas 76 fêmeas suínas lactantes de médio potencial genético com peso inicial de 207,0 $\pm 32,0 \mathrm{~kg}$ e ordem de parto de $3,53 \pm 2,11$, para avaliar níveis de treonina digestível na fase de lactação. Os animais foram distribuídos em delineamento experimental de blocos ao acaso, composto por quatro tratamentos $(0,589 ; 0,627 ; 0,665$ e $0,703 \%$ de treonina digestível) e 19 repetições, em que cada unidade experimental foi constituída por uma fêmea. Não houve efeito dos níveis de treonina digestível sobre o peso das fêmeas ao desmame, a espessura de toucinho (ET) e a composição de proteína corporal à desmama. A perda de peso das fêmeas durante a lactação reduziu de forma linear com o aumento do nível de treonina digestível. Os níveis de treonina digestível não influenciaram a variação da ET durante a lactação, mas afetaram a mobilização de proteína corporal, que reduziu linearmente com o aumento do nível de treonina digestível. Não houve efeito dos níveis de treonina digestível sobre os consumos de ração, de lisina e de energia digestível, entretanto, verificou-se aumento linear do consumo de treonina digestível, em razão do aumento de seu nível na dieta. Os níveis de treonina digestível não influenciaram a eficiência energética das fêmeas, o intervalo desmama-estro e o desempenho dos leitões e leitegadas. Fêmeas suínas lactantes de médio potencial genético exigem $0,589 \%$ de treonina digestível, correspondente ao consumo diário de $28,5 \mathrm{~g}$ e à relação treonina digestível: lisina digestível de $62 \%$.

Palavras-chave: mobilização de gordura, mobilização de proteína, produção de leite, proteína ideal, relação aminoacídica

\section{Digestible threonine levels in diets for lactating sows of medium genetic potential}

\begin{abstract}
Seventy and six lactating crossbred sows of medium genetic potential with initial weight of $207.0 \pm 32.0 \mathrm{~kg}$ and reproductive cycles order of $3.53 \pm 2.11$ were used to evaluate digestible threonine levels in the lactation phase. The animals were allotted to a randomized blocks experimental design with four treatments $(0.589,0.627,0.665$, and $0.703 \%$ of digestible threonine) and nineteen replications, in which each experimental unit was onsisted by a female. There was no effect of digestible threonine levels on the weight of sows at weaning time, fat thickness (FT) and corporal protein composition at weaning time. The loss of weight of the sows during the lactation reduced in a linear form with the increase of the digestible threonine level. There was no effect of digestible threonine levels on FT variation during the lactation, however affected the corporal protein mobilization that linearly reduced with the increase of the digestible threonine level. There was no effect of digestible threonine levels on feed intake, lysine and digestible energy, however, was observed linear increase of the intake of digestible threonine with its increase level in the diet. The digestible threonine levels did not influence the energy efficiency of the sows; weaning - estrus interval and the performance of the pigs and litters. Lactating sows of medium genetic potential require $0.589 \%$ of digestible threonine, corresponding to daily consumption of $28.5 \mathrm{~g}$ and a digestible threonine: digestible lysine ratio of $62 \%$.
\end{abstract}

Key Words: amino acids relation, fat mobilization, ideal protein, milk production, protein mobilization

\section{Introdução}

Tem-se constatado que dietas contendo inadequada concentração de aminoácidos e energia, para matrizes suínas na fase de lactação, podem reduzir a produção de leite e, conseqüentemente, o ganho de peso da leitegada (King et al., 1993). Além disso, o comprometimento do consumo de nutrientes na fase de lactação pode resultar em mobilização excessiva da reserva corporal (Webel et al., 2003), com efeitos diretos sobre o intervalo desmama-cio e o tamanho da leitegada subseqüente (Spencer et al., 2003), além de aumentar as falhas reprodutivas (King \& Williams, 1984). 
Dessa forma, a preocupação não deve ser somente quanto ao atendimento das exigências para a produção de leite e o crescimento da leitegada, mas também para o desempenho reprodutivo nos ciclos subseqüentes da fêmea suína.

Para as matrizes, o peso da leitegada tem sido determinante na exigência de aminoácidos, que, por sua vez, está significativamente correlacionada ao número de leitões (Auldist et al., 1998). À medida que aumenta o tamanho da leitegada, a demanda de nutrientes pela fêmea para mantença e produção da glândula mamária também aumenta (Kim et al., 1999), assim como a produção de leite (King, 1991), o que pode acarretar incremento da mobilização das reservas corporais, se a fêmea não suprir esta demanda por meio do consumo de alimento (Kim \& Easter, 2001).

Esses fatores, se não forem devidamente equacionados nos experimentos que visam determinar níveis de aminoácidos para as fêmeas suínas lactantes, podem levara interpretações errôneas acerca das necessidades nutricionais desses nutrientes para esses animais.

Além disso, tem-se constatado que, entre os aminoácidos, a treonina pode ser o primeiro limitante em dietas para fêmeas suínas em lactação, sobretudo quando maiores quantidades de leite são demandadas pela leitegada (Kim \& Easter, 2001) ou quando ocorre alta mobilização de tecidos corporais (Kim et al., 2001). Por isso, o teor adequado de treonina digestível para matrizes na fase de lactação pode possibilitar a expressão do potencial genético máximo, com concomitante redução na perda de peso e maximização da produção de leite e do ganho de peso da leitegada.

Nesse contexto, propôs-se realizar este estudo com o objetivo de avaliar níveis de treonina digestível em dietas para fêmeas suínas lactantes de médio potencial genético, dentro de um contexto de proteína ideal.

\section{Material e Métodos}

O experimento foi conduzido no Setor de Suinocultura, do Departamento de Zootecnia, do Centro de Ciências Agrárias, da Universidade Federal de Viçosa, no período de maio de 2004 a fevereiro de 2005, em Viçosa, MG.

Foram utilizadas 76 fêmeas mestiças de médio potencial genético, do primeiro ao sétimo parto, com ordem de parto de $3,53 \pm 2,11$ e peso inicial de $207,0 \pm 32,0 \mathrm{~kg}$, distribuídas em delineamento experimental de blocos ao acaso composto por quatro tratamentos $(0,589 ; 0,627 ; 0,665$ e $0,703 \%$ de treonina digestível, correspondentes, respectivamente, às relações de 0,$62 ; 0,66 ; 0,70$ e $0,74 \%$ com a lisina digestível) e 19 repetições (blocos), no qual cada unidade experimental foi composta de uma fêmea. Na formação dos blocos, foram considerados o peso corporal e a ordem de parto das fêmeas.
As dietas experimentais (Tabela 1) foram formuladas para atender às exigências em aminoácidos, com exceção da treonina. Além disso, exceto a treonina, cujos níveis e relações variaram, as relações dos demais aminoácidos com a lisina atenderam às relações mínimas preconizadas por Kim et al. (2001). Os diferentes níveis de treonina digestível foram obtidos pela inclusão de L-treonina em substituição ao ácido glutâmico.

As dietas experimentais foram fornecidas as fêmeas após o parto até o desmame, efetuando-se o fornecimento de $1,8 \mathrm{~kg}$ de ração para mantença mais $0,35 \mathrm{~kg}$ de ração por leitão em amamentação, em até três refeições diárias. As sobras de ração do comedouro foram coletadas e pesadas após cada refeição para determinação do consumo diário de ração. Durante a lactação, os leitões tiveram acesso à água por meio de bebedouros do tipo chupeta, mas não receberam ração.

As fêmeas foram pesadas 24 horas após o parto e ao desmame, realizado no 21 o dia de lactação. As leitegadas também foram pesadas 24 horas após o nascimento e ao desmame.

A espessura de toucinho (ET) foi medida, por meio de aparelho de ultra-sonografia, no ponto $\mathrm{P}_{2}(6,5 \mathrm{~cm}$ da linha dorsal no nível da 10 a costela) 24 horas após o parto e ao desmame. Ao final do período de lactação, foi estimada a produção de leite das fêmeas com base no ganho de peso do leitão no período, tamanho da leitegada e duração da lactação, de acordo com a equação proposta por Ferreira et al. (1988): Produção de leite $(\mathrm{kg} / \mathrm{dia})=[(4,27 \mathrm{x}$ ganho de peso do leitão no período, $\mathrm{kg}$ ) x número de leitões]/número de dias de lactação.

O balanço de energia das fêmeas durante a lactação foi estimado pelo modelo de equações para predição da exigência nutricional dos suínos (modelo lactacional), publicado pelo NRC (1998), em que o consumo diário de energia durante o período experimental é calculado pela multiplicação do conteúdo de energia da dieta pelo consumo diário. A exigência de energia para mantença foi calculada com base no peso corporal (PC) das fêmeas: energia de mantença $(\mathrm{MJ} E M /$ dia $)=0,44 \mathrm{MJ}$ de $\mathrm{EM} \times \mathrm{PC}^{0,75}$. O peso corporal utilizado para o cálculo foi a média entre os pesos inicial (24 horas após o parto) e final (desmama).

Para estimar a exigência de energia para a produção de leite, foi calculada a quantidade de energia transferida da fêmea para a leitegada: energia para a produção de leite (MJ energia bruta/dia $)=[(4,92 \times$ ganho médio da leitegada, $\mathrm{g} / \mathrm{dia})$ - (90 x número de leitões)] x 0,00419. Assumindo-se que a eficiência de energia da dieta para a produção de leite é de 0,72 e que a eficiência de energia mobilizada do tecido é de 0,88 , determinou-se o balanço de energia (BE) como: $\mathrm{BE}$ $(\mathrm{MJ} / \mathrm{dia})=$ consumo energia $-($ energia de mantença + energia para produção de leite). 
Tabela 1 - Composições centesimal e nutricional das dietas experimentais ${ }^{1}$

Table 1 - Percentage and nutritional compositions of the experimental diets

\begin{tabular}{|c|c|c|c|c|}
\hline \multirow[t]{2}{*}{$\begin{array}{l}\text { Ingrediente } \\
\text { Ingredient }\end{array}$} & \multicolumn{4}{|c|}{$\begin{array}{c}\text { Nível de treonina digestível (\%) } \\
\text { Digestible threonine level }\end{array}$} \\
\hline & 0,589 & 0,627 & 0,665 & 0,703 \\
\hline Sorgo baixo tanino (Sorgum low tanning) & 63,760 & 63,760 & 63,760 & 63,760 \\
\hline Farelo de soja, $45 \%$ PB (Soybean meal, $45 \%$ CP) & 26,761 & 26,761 & 26,761 & 26,761 \\
\hline Óleo de soja (Vegetable oil) & 5,156 & 5,156 & 5,156 & 5,156 \\
\hline Fosfato bicálcico (Dicalcium phosphate) & 1,901 & 1,901 & 1,901 & 1,901 \\
\hline Calcário (Limestone) & 1,347 & 1,347 & 1,347 & 1,347 \\
\hline Mistura mineral $^{1}$ (Mineral mix) $^{2}$ & 0,100 & 0,100 & 0,100 & 0,100 \\
\hline Mistura vitamínica ${ }^{2}$ (Vitamin mix) & 0,100 & 0,100 & 0,100 & 0,100 \\
\hline Sal (Salt) & 0,476 & 0,476 & 0,476 & 0,476 \\
\hline ВНT & 0,010 & 0,010 & 0,010 & 0,010 \\
\hline L-lisina $\mathrm{HCl}(\mathrm{L}-\mathrm{Lys} \mathrm{HCl})$ & 0,228 & 0,228 & 0,228 & 0,228 \\
\hline DL-metionina (DL-Met) & 0,031 & 0,031 & 0,031 & 0,031 \\
\hline L-treonina $(L-t h r)$ & 0,000 & 0,039 & 0,077 & 0,116 \\
\hline Ácido glutâmico (Glutamic acid) & 0,130 & 0,091 & 0,053 & 0,014 \\
\hline Relação treonina:lisina (Thr:Lys ratio) & 62 & 66 & 70 & 74 \\
\hline PB $(\%)(C P)$ & 18,110 & 18,110 & 18,110 & 18,110 \\
\hline $\mathrm{EM}(\mathrm{kcal} / \mathrm{kg})(M E)$ & 3.400 & 3.400 & 3.400 & 3.400 \\
\hline Lisina total (Total Lys) (\%) & 1,063 & 1,063 & 1,063 & 1,063 \\
\hline Lisina digestível (\%) (Digestible Lys) & 0,950 & 0,950 & 0,950 & 0,950 \\
\hline Met + cis digestível $(\%)($ Digestible Met + Cys $)$ & 0,520 & 0,520 & 0,520 & 0,520 \\
\hline Treonina digestível (\%) (Digestible Thr) & 0,589 & 0,627 & 0,665 & 0,703 \\
\hline Triptofano digestível (\%) (Digestible Trp) & 0,206 & 0,206 & 0,206 & 0,206 \\
\hline Valina digestível (\%) (Digestible Val) & 0,785 & 0,785 & 0,785 & 0,785 \\
\hline $\mathrm{Ca}(\%)$ & 1,100 & 1,100 & 1,100 & 1,100 \\
\hline P disponível (\%) (Available P) & 0,460 & 0,460 & 0,460 & 0,460 \\
\hline $\mathrm{Na}(\%)$ & 0,220 & 0,220 & 0,220 & 0,220 \\
\hline
\end{tabular}

${ }_{1}$ Conteúdo/kg (Content/kg): Fe, $100 \mathrm{~g} ; \mathrm{Cu}, 10 \mathrm{~g} ; \mathrm{Co}, 0,2 \mathrm{~g} ; \mathrm{Mn}, 30 \mathrm{~g} ; \mathrm{Zn}, 100 \mathrm{~g} ; \mathrm{I}, 1,0 \mathrm{~g} ; \mathrm{Se}, 0,3$ g, excipiente q.s.p. (vehicle q.s.p.), 1.000 g.

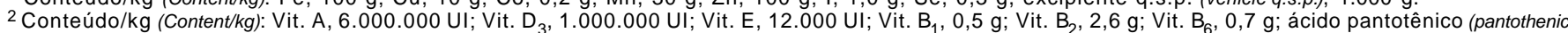
acid), $10 \mathrm{~g}$; Vit. $\mathrm{K}_{3}, 1,5 \mathrm{~g}$; ácido nicotínico (nicotinic acid), $22 \mathrm{~g}$; Vit. B12, 0,015 g; ácido fólico (folic acid), 0,2 g; biotina (biotin), $0,05 \mathrm{~g} ;$ colina (choline), $100 \mathrm{~g}$ e excipiente q.s.p. (vehicle q.s.p.), $1.000 \mathrm{~g}$

Para estimar a quantidade de gordura mobilizada durante a lactação, foram estimadas as quantidades de gordura corporal 24 horas após o parto e ao desmame a partir das variáveis $\mathrm{PC}$ e ET, de acordo com a equação de regressão proposta por CVB (1994): gordura corporal $(\mathrm{kg})=-11,58+$ $(0,1027 \times \mathrm{PC}, \mathrm{kg})+\left(1,904 \times \mathrm{ET} \mathrm{P}_{2}, \mathrm{~mm}\right)$.

Para estimar a quantidade de proteína mobilizada du rante a lactação, também foram estimadas as quantidades de proteína corporal 24 horas após o parto e ao desmame a partir das variáveis PC e ET, conforme equação de regressão citada por Clowes et al. (2003): proteína corporal $(\mathrm{kg})=$ $-2,3+\left[(0,19 \times \mathrm{PC}, \mathrm{kg})-\left(0,22 \times \mathrm{ET} \mathrm{P}_{2}, \mathrm{~mm}\right)\right]$.

Considerou-se que toda gordura corporal mobilizada foi oriunda do tecido adiposo. A quantidade de perda de tecido adiposo e de proteína durante a lactação foi calculada considerando-se que o tecido adiposo contém $900 \mathrm{~g}$ de gordura/ $\mathrm{kg}$ e o tecido protéico, $230 \mathrm{~g}$ de proteína $/ \mathrm{kg}$. Para estimar a quantidade de energia mobilizada da gordura e de proteína utilizada para a produção de leite, considerou-se o conteúdo de energia de 39,4 e $23,5 \mathrm{MJ} / \mathrm{kg}$, respectivamente, para gordura e proteína (NRC, 1998).

A eficiência energética das fêmeas foi estimada em razão do consumo de ração e da produção de leitões. Esse método consiste em estimar a quantidade energética de PC mobilizada pela fêmea durante a lactação, a quantidade de energia ingerida por meio do consumo de ração e a quantidade de energia gerada em razão da produção de leitões, determinando a relação entre essas variáveis. A quantidade de energia produzida por quilograma de carne de suíno em crescimento foi estimada em 16,49 Mcal EM/kg de proteína e 12,91 Mcal $\mathrm{EM} / \mathrm{kg}$ de gordura e a quantidade de energia produzida por $\mathrm{kg}$ de peso perdido pela fêmea durante a lactação, em 10,52 Mcal EM/kg (Whittemore \& Elsley, 1979).

A temperatura e a umidade relativa do ambiente foram registradas diariamente às $7,12 \mathrm{e} 17 \mathrm{~h}$, durante todo o período experimental, por meio de um conjunto de termômetros de máxima e mínima, de bulbo seco e bulbo úmido e de globo negro instalados no centro da sala, à meia altura do corpo dos animais. Os valores registrados foram, posteriormente, convertidos no índice de temperatura de globo e umidade (ITGU), segundo Buffington et al. (1981), caracterizando o ambiente térmico em que os animais foram mantidos.

As fêmeas foram observadas diariamente para detecção do estro, levando-se o cachaço duas vezes ao dia às baias das fêmeas. Foram consideradas em estro as fêmeas que 
apresentaram reflexo de tolerância ao homem na presença do macho. As datas do desmame e de manifestação do estro foram consideradas no cálculo do intervalo desmama-estro. Uma vez diagnosticado o estro, as matrizes foram inseminadas artificialmente, com a primeira cobertura realizada 12 horas após a manifestação do estro.

Os dados foram submetidos à análise estatística utilizando-se o programa estatístico SAS (1996). A estimativa da exigência de treonina foi determinada pelo modelo de regressão linear ou quadrática, segundo o melhor ajuste obtido para cada variável. As variáveis peso dos leitões ao desmame e ganho de peso dos leitões foram analisadas pela covariável peso dos leitões 24 horas pós-parto, ao passo que peso de leitegada ao desmame e ganho de peso de leitegada, pela covariável peso de leitegada 24 horas pós-parto.

\section{Resultados e Discussão}

Durante o período experimental, a temperatura média do ar das salas foi de $20,7 \pm 3,3^{\circ} \mathrm{C}$, a umidade relativa média de $77,7 \pm 8,3 \%$, a temperatura média de globo negro de $21,0 \pm$ $3,1^{\circ} \mathrm{C}$ e o ITGU médio calculado de $68,0 \pm 4,2$. A temperatura média do ar obtida neste estudo pode ser considerada termoneutra, por estar na faixa de temperatura de 16 a $22^{\circ} \mathrm{C}$, considerada ideal para esta categoria animal (Black et al., 1993; Bragança et al., 1998).

Não foi constatada diferença $(\mathrm{P}>0,10)$ entre os tratamentos para os pesos das fêmeas ao desmame (Tabela 2). Verificou-se efeito dos tratamentos sobre a variação de pesos total $(\mathrm{P}<0,07)$ e percentual $(\mathrm{P}<0,05)$ das fêmeas durante a lactação, sendo que as perdas reduziram de forma linear

Tabela 2 - Desempenho de fêmeas suínas em função do nível dietético de treonina digestível

Table 2 - Performance of sows in function of the dietary level of digestible threonine

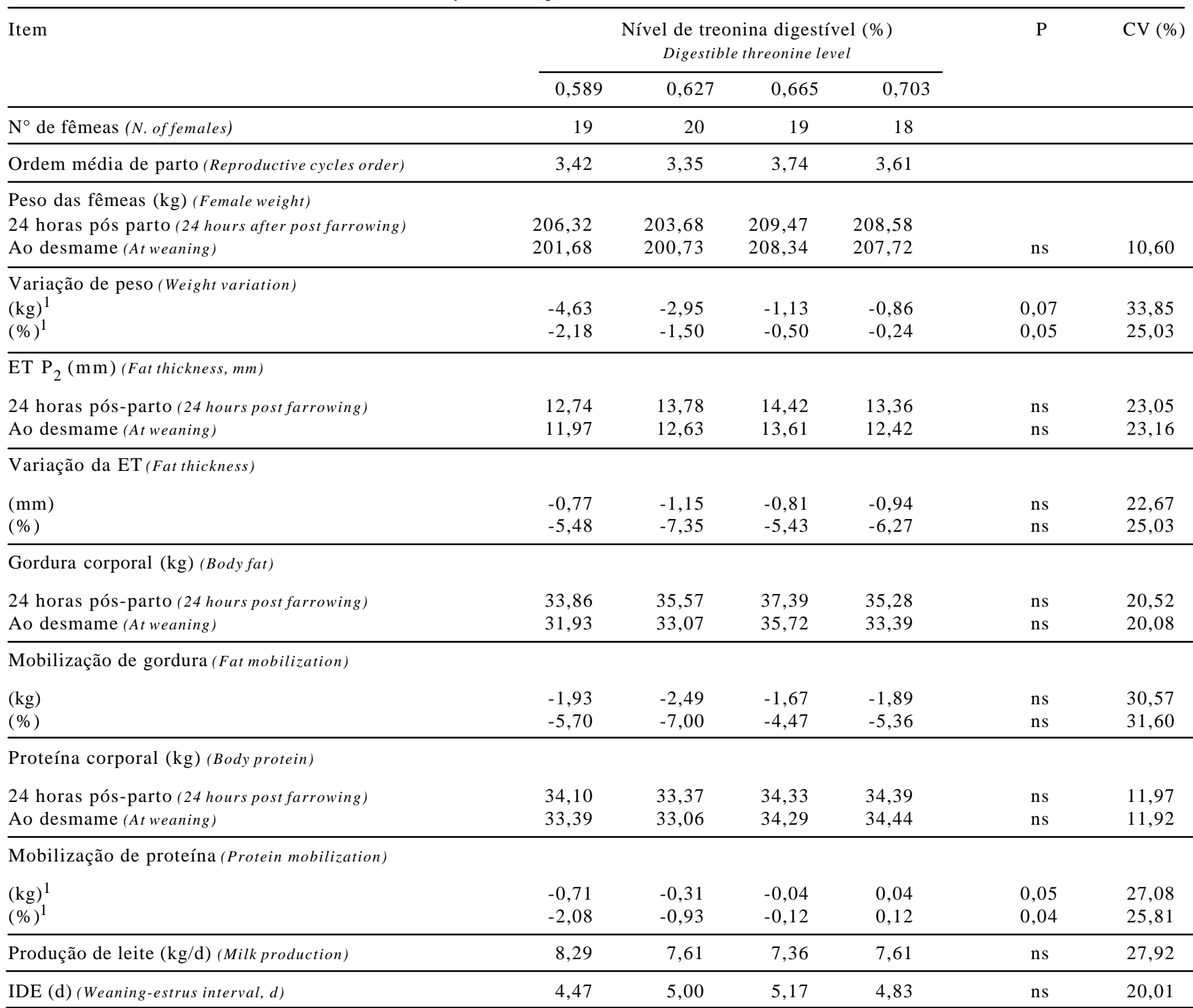

${ }^{1}$ Efeito linear (Linear effect); ${ }^{n s}$ Efeito não-significativo, $P>0,10$ (Not significant effect). 
com o aumento do nível de treonina digestível na dieta (Figura 1).

Não houve efeito $(\mathrm{P}>0,10)$ dos níveis de treonina digestível sobre a ET e as composições de proteína e gordura corporal ao desmame e sobre as variações total e percentual da ET durante a lactação.

Constatou-se efeito dos tratamentos sobre as mobilizações total $(\mathrm{P}<0,05)$ e percentual $(\mathrm{P}<0,04)$ de proteína corporal, que reduziram de forma linear conforme aumentaram os níveis de treonina digestível na dieta (Figura 2).

Os níveis de treonina digestível não influenciaram $(\mathrm{P}>0,10)$ a produção diária estimada de leite; os valores médios estimados variaram de 6,61 a $7,52 \mathrm{~kg} /$ dia e podem ser considerados baixos e representativos de matrizes de médio potencial de produção, uma vez que as matrizes contemporâneas de alto potencial genético, conforme Boyd et al. (2000), podem apresentar produção diária estimada de leite superior a 10,0 kg. Sauber et al. (1998), por sua vez, em

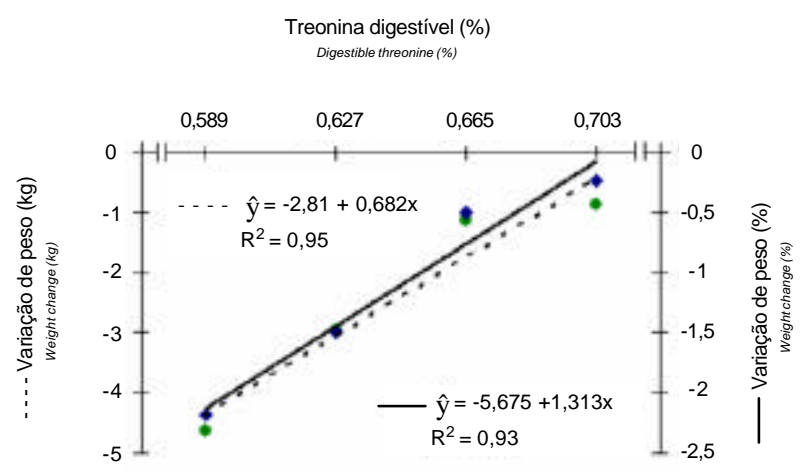

Figura 1 - Variações absoluta e percentual de peso corporal, em função do nível dietético de treonina digestível.

Figure 1 - Absolute and percentage changes of body weight according to the dietary level of digestible threonine.

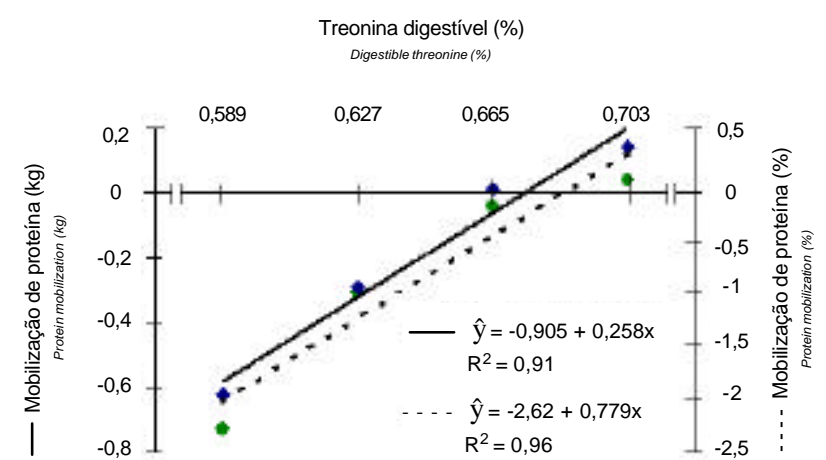

Figura 2 - Mobilizações absoluta e percentual de proteína corporal, em função do nível dietético de treonina digestível.

Figure 2 - Absolute and percentage mobilizations of body protein according to the dietary level of digestible threonine. estudo conduzido com fêmeas suínas lactantes de alta capacidade de deposição de tecido magro na carcaça, estimaram a produção de leite em $10,7 \mathrm{~kg} / \mathrm{dia}$.

Não houve efeito $(P>0,10)$ dos tratamentos sobre o IDE, observando-se valor máximo de 5,17 dias, considerado satisfatório, pois, segundo Sesti \& Sobestiansky (1998), o alvo de produtividade estabelecido para este parâmetro nas granjas de suínos é de cinco dias.

Observou-se, neste estudo, baixa mobilização de tecidos corporais, mesmo com o menor nível de treonina digestível (0,589\%), que resultou em perda média máxima de 2,18 e $1,97 \%$, respectivamente, de variação de peso e de proteína corporal. A redução de proteína corporal, observada neste estudo, foi inferior à observada por Clowes et al. (2003), que relataram que as fêmeas suínas podem sustentar uma perda de até $12,0 \%$ de sua massa protéica corporal no transcorrer da lactação, sem influenciar negativamente o crescimento dos leitões e da leitegada.

A baixa mobilização de tecidos corporais, obtida neste estudo, pode ser indicativo de que a treonina não foi limitante, pois, mesmo no nível basal, a mobilização de tecidos, caracterizada pela perda de peso, foi baixa, não influenciando significativamente os desempenhos produtivo e reprodutivo das fêmeas.

Em razão do ajuste do fornecimento de alimento conforme o tamanho das leitegadas, que foram equalizadas após o parto, o consumo diário de ração e, conseqüentemente, os de lisina e energia metabolizável não variaram $(\mathrm{P}>0,10)$ entre os tratamentos (Tabela 3). Por não ter ocorrido variação no consumo diário de ração entre os tratamentos, constatou-se aumento linear $(\mathrm{P}<0,01)$ no consumo diário de treonina digestível com o incremento de seu nível na dieta, segundo a equação: $\hat{Y}=10,207+35,503 X\left(R^{2}=0,96\right)$.

Os consumos diários de lisina digestível atenderam ao valor mínimo de $45 \mathrm{~g} / \mathrm{dia}$ de lisina total, preconizado por Dourmad et al. (1998), e de 40 g/dia de lisina digestível, recomendado por Cota et al. (2003), para fêmeas lactantes de médio potencial genético, para que apresentem perda mínima de peso corporal durante a lactação e não comprometam seu desempenho e de suas leitegadas.

Por não ter ocorrido efeito $(\mathrm{P}>0,10)$ dos tratamentos sobre as exigências de energia para a mantença e a produção de leite e o consumo diário de energia, não se constatou variação $(\mathrm{P}>0,10)$ dos níveis de treonina da dieta sobre o balanço energético. Deve-se considerar que todas as dietas apresentaram balanço energético positivo, o que não é um resultado normal para fêmeas na fase de lactação. Uma explicação possível para esta resposta é a baixa produção de leite e, portanto, a baixa exigência de energia para a produção de leite. Os níveis de treonina digestível 
Tabela 3 - Consumos de ração e nutrientes e balanço e eficiência energéticos de fêmeas suínas, em função do nível dietético de treonina digestível

Table 3 - Feed and nutrient intakes and balance and energy efficiency of sows according to the dietary level of digestible threonine

\begin{tabular}{|c|c|c|c|c|c|c|}
\hline \multirow[t]{2}{*}{ Item } & \multicolumn{4}{|c|}{$\begin{array}{c}\text { Nível de treonina digestível (\%) } \\
\text { Digestible threonine level }\end{array}$} & \multirow[t]{2}{*}{$\mathrm{P}$} & \multirow[t]{2}{*}{$\mathrm{CV}(\%)$} \\
\hline & 0,589 & 0,627 & 0,665 & 0,703 & & \\
\hline \multicolumn{7}{|l|}{ Consumo (Intake) } \\
\hline Ração fêmea (kg/d) (Female diet) & 4,841 & 4,775 & 4,792 & 4,694 & $\mathrm{~ns}$ & 11,17 \\
\hline Treonina digestível $(\mathrm{g} / \mathrm{d})^{1}$ (Digestible threonine) & 28,5 & 29,9 & 31,9 & 33,0 & 0,001 & 10,96 \\
\hline Consumo energia dig. ( $\mathrm{Mcal} / \mathrm{d})$ (Digestible energy intake) & 16,94 & 16,66 & 16,80 & 16,66 & ns & 14,20 \\
\hline Energia mantença (Mcal/d) (Maintenance energy) & 5,66 & 5,62 & 5,76 & 5,75 & ns & 11,71 \\
\hline Energia leite (Mcal/d) (Milk energy) & 8,38 & 7,78 & 7,29 & 7,55 & ns & 27,92 \\
\hline Balanço energético (Mcal/d) (Energy balance) & 2,89 & 3,25 & 3,74 & 3,35 & ns & 39,58 \\
\hline Eficiência energética (Energy efficiency) & 1,49 & 1,54 & 1,58 & 1,43 & ns & 26,50 \\
\hline
\end{tabular}

${ }^{1}$ Efeito linear (Linear effect); ns Efeito não-significativo (Not significant effect).

Tabela 4 - Desempenho de leitegadas de fêmeas suínas em função do nível dietético de treonina digestível Table 4 - Performance of litters of sows in function of the dietary digestible threonine level

\begin{tabular}{|c|c|c|c|c|c|c|}
\hline \multirow[t]{2}{*}{ Item } & \multicolumn{4}{|c|}{$\begin{array}{c}\text { Nível de treonina digestível }(\%) \\
\text { Digestible threonine level }\end{array}$} & \multirow[t]{2}{*}{$\mathrm{P}$} & \multirow[t]{2}{*}{$\mathrm{CV}(\%)$} \\
\hline & 0,589 & 0,627 & 0,665 & 0,703 & & \\
\hline \multicolumn{7}{|l|}{$\mathrm{N}^{\circ}$ de leitões ( $N$. of piglets) } \\
\hline 24 horas pós-parto (24 hours post farrowing) & 10,00 & 9,53 & 9,59 & 9,83 & & \\
\hline Ao desmame (At weaning) & 9,58 & 9,25 & 9,11 & 9,44 & ns & 12,31 \\
\hline \multicolumn{7}{|l|}{ Leitões (kg) (Piglets) } \\
\hline Peso 24 horas pós-parto (Weight 24 hours post farrowing) & 1,36 & 1,33 & 1,27 & 1,30 & ns & 15,16 \\
\hline Peso ao desmame (Weaning weight) & 5,53 & 5,36 & 5,15 & 5,16 & ns & 17,17 \\
\hline Ganho de peso (g/d) (Weight gain) & 196 & 192 & 184 & 183 & ns & 21,48 \\
\hline \multicolumn{7}{|l|}{ Leitegada (kg) (Litter) } \\
\hline 24 horas pós-parto ( 24 hours post farrowing) & 13,55 & 12,68 & 12,18 & 12,79 & ns & 17,29 \\
\hline Ganho de peso (kg/d) (Weight gain) & 1,88 & 1,75 & 1,65 & 1,71 & ns & 22,60 \\
\hline
\end{tabular}

ns Efeito não-significativo (Not significant effect).

também não influenciaram $(\mathrm{P}>0,10)$ a eficiência energética das fêmeas.

Não houve efeito $(\mathrm{P}>0,10)$ das dietas sobre o desempenho dos leitões e das leitegadas (Tabela 4). Os ganhos de peso dos leitões e das leitegadas, obtidos neste estudo, podem caracterizar as matrizes como animais de médio potencial genético, uma vez que o desempenho das leitegadas foi inferior ao observado em outros estudos, como o de Cooper et al. (2001), que, determinando a exigência de treonina para matrizes de alta capacidade produtiva, obtiveram ganhos diários de peso das leitegadas superiores a $2,4 \mathrm{~kg}$.

De acordo com os resultados obtidos, pode-se inferir que, embora o aumento do nível de treonina digestível na dieta tenha proporcionado redução da mobilização de tecidos corporais durante a lactação, o nível de $0,589 \%$ de treonina digestível, correspondente à relação treonina digestível: lisina digestível de $62,0 \%$ e ao consumo diário de 28,5 g de treonina digestível, foi satisfatório para manter o desempenho produtivo das fêmeas. Este resultado está de acordo com a recomendação de Kim \& Easter (2001), que estabeleceram relação de $62,0 \%$ (com mobilização tissular de $30,0 \%$ ), e de Rostagno et al. (2000), que propõem relação de $61,0 \%$ e consumo diário de $29,4 \mathrm{~g}$ de treonina digestível. Por outro lado, o resultado foi inferior às relações de 70,0 e 72,0\% recomendadas pelo NRC (1998) e ARC (1981), respectivamente, e as estimativas, pelo método fatorial, de relações entre 65,0 e 71,0\% de Dourmad et al. (1991). Relação treonina:lisina digestíveis superior à obtida neste estudo também foi proposta por Rostagno et al. (2005) e Kim et al. (2001), de 64,0 e 69,0\%, respectivamente.

Com relação ao nível de treonina digestível para matrizes lactantes, Kansas (1994) estabeleceu exigência de 0,50\%, 
NRC (1998) de 0,58\%, Rostagno et al. (2000) de 0,49\% e Reese et al. (2000) de 0,67\% de treonina total. Entretanto, Rostagno et al. (2005) propõem nível de $0,582 \%$ de treonina digestível, próximo ao resultado obtido neste estudo. Por outro lado, Kim et al. (2001) recomendam o nível de treonina digestível de $0,625 \%$, superior aos anteriormente citados e próximo ao resultado obtido neste trabalho.

Com relação ao consumo diário de treonina para porcas multíparas em lactação, a exigência tem sido estimada em $31 \mathrm{~g}$ de treonina total diário, para minimizar a perda de peso corporal (Westermeier et al., 1998), e $28 \mathrm{~g}$ de treonina total ao dia, para maximizar a produção de leite (Paulicks et al., 1998). Reese et al. (2000) estimaram em 36,7 g a exigência diária de treonina total para fêmeas, com duração do período de lactação de 21 dias.

Por outro lado, Cooper et al. (2001) estimaram a exigência de treonina em 14,3 g por $\mathrm{kg}$ de ganho de peso da leitegada e a exigência diária de treonina para minimizar a mobilização de tecidos corporais, em 37, 40 e $38 \mathrm{~g}$, respectivamente, para fêmeas de $1 \underline{\mathrm{O}}, 2 \underline{\mathrm{O}}$ e $3 \underline{\mathrm{O}}$ partos.

A variação entre as recomendações de exigência treonina para porcas em lactação pode ser atribuída, entre outros fatores, à ordem de parto das matrizes e às diferenças genéticas, uma vez que grande parte das estimativas de exigências de proteína e de aminoácidos baseia-se em estudos nos quais o ganho de peso das leitegadas foi menor que $1,5 \mathrm{~kg} / \mathrm{dia}$, inferior também ao dos rebanhos contemporâneos, principalmente, relacionado à maior produção de leite.

\section{Conclusões}

O nível de 0,589\% de treonina digestível, correspondente ao consumo diário de 28,5 g e à relação treonina digestível:lisina digestíveis de $62 \%$, atende às exigências de fêmeas suínas lactantes de médio potencial genético.

\section{Literatura Citada}

AGRICULTURE RESEARCH COUNCIL - ARC. The nutrient requirement of pigs. Slough: Commonwealth Agriculture Bureaux, 1981.307p.

AULDIST, D.E.; MORRISH, L.; EAOSN, P.E. The influence of litter size on milk production of sows. Animal Science, v.63, p.333-337, 1998.

BLACK, J.L.; MULLAN, M.L.; LORSCHY, M.L. et al. Lactation in the sow during heat stress. Livestock Production Science, v.35, p.153-170, 1993.

BOYD, R.D.; TOUCHETTE, K.J.; CASTRO, G.C. et al. Recent advances in amino acid and energy nutrition of prolific sows: review. Journal of Animal Science, v.13, p.1638, 2000.

BRAGANÇA, M.; MOUNIER, M.; PRUNIER, A. Does feed restriction mimic the effects of increased ambient temperature in lactating sows? Journal of Animal Science, v.76, p.20172024, 1998
BUFFINGTON, D.E.; COLAZZO-AROCHO, A.; CANTON, G.H. et al. Black globe-humidity index (BGHI) as comfort equation for dairy cows. Transaction ASAE, v.24, p.711-714, 1981.

CEnTRAL VEevoederbuREAU - CVB. Normen voor dragende zeugen (Requirements for pregnant sows). Lelystad: Central Veevoederbureau, 1994. p.51 (Documentation Report, 9).

CLOWES, E.J.; AHERNE, F.X.; FOXCROFT, G.R. et al. Selective protein loss in lactating sows is associated with reduced litter growth and ovarian function. Journal of Animal Science, v.81, p.753-764. 2003.

COOPER, D.R.; PATIENCE, J.F.; ZIJLSTRA, R.T. et al. Effect of nutrient intake in lactation on sow performance: determining the threonine requirement of the high-producing lactating sow. Journal of Animal Science, v.79, p.23782387, 2001.

COTA, T.S.; DONZELE, J.L.; OLIVEIRA, R.F.M. et al. Níveis de lisina em ração de lactação para fêmeas suínas primíparas. Revista Brasileira de Zootecnia, v.32, n.1, p.115-122, 2003.

DOURMAD, J.Y.; NOBLET, J.; ETIENNE, M. Effect of protein and lysine supply on performance, nitrogen balance, and body composition changes of sows during lactation. Journal of Animal Science, v.76, p.542-550. 1998.

DOURMAD, J.Y.; ETIENNE, M.; NOBLET, J. Contribution à l'etude des besoins en acides aminés delatruieenlactation. Journal Recherche Porcine, v.23, p.61-68. 1991.

FERREIRA, A.S.; COSTA, P.M.A.; PERREIRA, J.A.A. et al. Estimativas de produção de leite de porca. Revista Brasileira de Zootecnia, v.17, n.3, p.203-211, 1988.

KANSAS SWINE NUTRITION GUIDE. Cooperative extension service. Kansas: Kansas State University, 1994. 12p.

KIM, S.W.; OSAKA, W.L.; HURLEY, W.L. et al. Mammary gland growth as affected by litter size in lactating sows: impact on lysine requirement. Journal of Animal Science, v.77, p.3316$3321,1999$.

KIM, S.W.; EASTER, R.A. Nutrient mobilization form body tissues as influenced by litter size in lactating sows. Journal of Animal Science, v.79, p.2179-2186, 2001.

KIM, S.W.; BAKER, D.H.; EASTER, R.A. Dynamic ideal protein and limiting amino acids for lactating sows: the impact of amino acid mobilization. Journal of Animal Science, v.79, p.23562366, 2001.

KING, R.H. Response of pregnant gilts to dietary protein as determined by nitrogen retention. Journal of Animal Science, v.69 (Suppl.1), p.361-362 (Abstr.), 1991.

KING, R.H.; TONER, M.S.; DOVE, C.S. The response of firstlitter sows to dietary protein level during lactation. Journal of Animal Science, v.71, p.2457-2463, 1993.

KING, R.H.; WILLIAMS, I.H. The effect of nutrition on the reproductive performance of first-litter sows. 1. Feeding level during lactation and between weaning and mating. Animal Production, v.38, p.241-247, 1984.

NATIONAL RESEARCH COUNCIL - NRC. Nutrients requirements of swine. 10.ed. Washington, D.C.: National Academic of Science, 1998. 189p.

PAULICKS, B.R.V.; WESTERMEIER, C.; KIRCHGESSNER, M. Milchmenge und milchinhaltsstoffe bei Sauen in Abhangigkeit von der threoninversorgung. 2. Mitteilung zumm Threoninbedarf laktierender Sauen. Journal of Animal Physiology Animal Nutrition, v.79, p.102-111, 1998.

REESE, D.E.; THALER, R.C.; BRUMM, M.C. et al. [2000].Swine nutrition guide. Disponível em: http://ianrwww.unl.edu/pubs/ swine/ec273.htm. Acesso em: 1/9/2004.

ROSTAGNO, H.S.; ALBINO, L.F.T.; DONZELE, J.L. et al. Composição de alimentos e exigências nutricionais. Tabelas brasileiras para aves e suínos. Viçosa, MG: Universidade Federal de Viçosa, 141p. 2000.

ROSTAGNO, H.S.; ALBINO, L.F.T.; DONZELE, J.L. et al. Composição de alimentos e exigências nutricionais. 
Tabelas brasileiras para aves e suínos. Viçosa, MG: Universidade Federal de Viçosa, 2005. 186p.

SAUBER, T.E.; STAHLY, T.S.; WILLIAMS, N.H. et al. Effect of lean growth genotype and dietary amino acid regimen on the lactational performance of sows. Journal of Animal Science, v.76, p.1098-1111, 1998.

STATISTICAL ANALYSIS SYSTEM - SAS.User's guide. version 6, 4.ed. Cary: 1996. 1686p.

SESTI, L.A.C.; SOBESTIANSKY, J. Alvos de produtividade. In: SOBESTIANSKY, J.; WENTZ, I.; SILVEIRA, P.R.S. et al. (Eds.) Suinocultura intensiva: produção, manejo e saúde do rebanho. Brasília: Embrapa-SPI; Concórdia: Embrapa-CNPSa, 1998. p.27-44.

SPENCER, J.D.; BOYD, R.D.; CABRERA, R. et al. Early weaning to reduce tissue mobilization in lactating sows and milk supplementation to enhance pig weaning weight during extreme heat stress. Journal of Animal Science, v.81, p.2041-2052, 2003.
WEBEL, D.M.; SPENCER, J.D.; UOTOO-TICE, E.R. et al. Sow nutrition for maximum prolificacy. In: CONGRESSO BRASILEIRO DE VETERINÁRIOS ESPECIALISTAS EM SUÍNOS, 11., 2003, Goiânia. Anais... Goiânia: ABRAVES, 2003. p.3-14.

WESTERMEIER, C.; PAULICKS, B.R.V.; KIRCHGESSNER, M. Futteraufnahme und Lebendmasseentwicklung von Sauen und Ferkeln wahrend der Laktation in Abhangigkeit von der Threoninversorgung der Sauen. 1. Mitteilung zum Threoninbedarf laktierender Sauen. Journal of Animal Physiology Animal Nutrition, v.79, p.33-45, 1998.

WHITTEMORE, C.T.; ELSLEY, F.W.H. Practical pig nutrition 2.ed. University of Edinburgh: Farming Press, 1979. 190p.

Recebido: 31/7/2006 Aprovado: $1 / 6 / 2007$ 